\title{
Factors Affecting Sleep Quality Among the University Students in Bangladesh: A Cross-Sectional Structured Interview Study
}

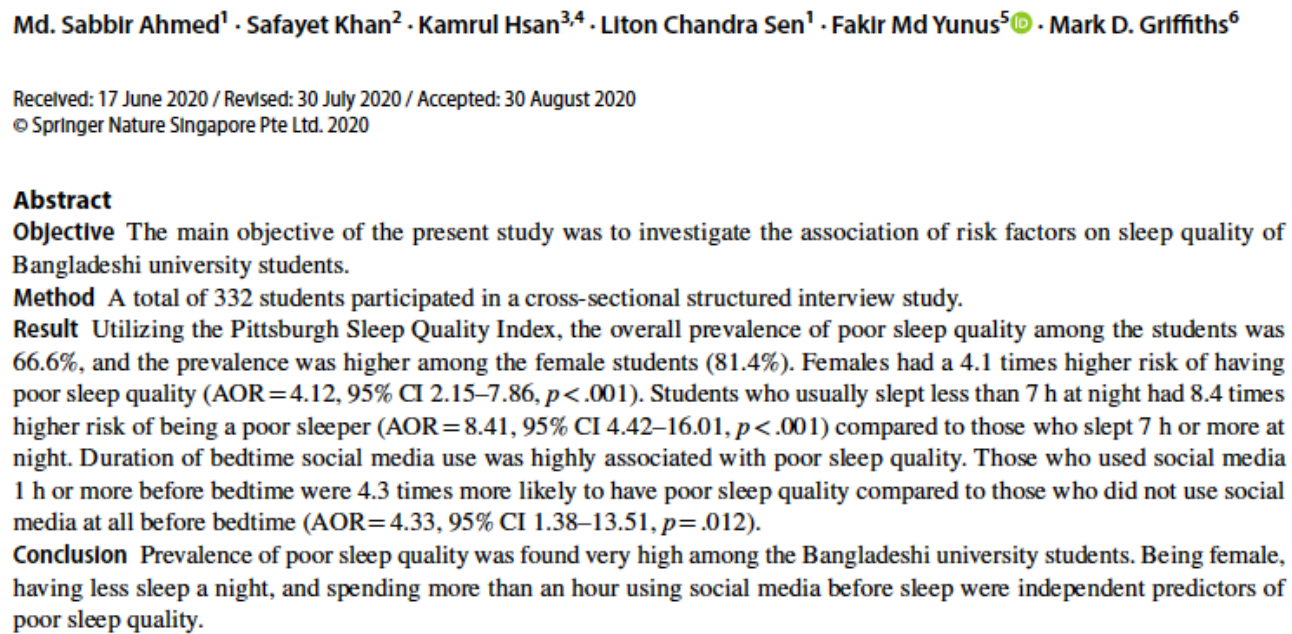

\section{Introduction}

Sleep is a naturally recurring state of mind and body, which is identified by periodically altered consciousness, relatively inhibited sensory activity, reduced muscle activity and inhibition of nearly all voluntary muscles [1,2]. It is important for maintaining good health and insufficient sleep can affect our mood and wellbeing [3]. Recently, not only the quantity but also the quality of sleep has been the issue of much attention and discussion. Quality of sleep is also crucial for better understanding of sleep-related health outcomes [4,5]. A quality sleep may depends upon "one's satisfaction of the sleep experience, integrating aspect of sleep initiation, sleep maintenance, sleep quantity, and refreshment upon awakening" [6]. Sleep helps to restore physical and mental functions and allow body system to repair tissues [7]. In addition, Many hormones (e.g., growth hormone) are also produced while sleeping [8]. Previous studies demonstrated a complex and multiple relationship of genetics, social and environmental factors, and other comorbidities with quantity of sleep $[9,10]$.

Although, the National Sleep Foundation (NSF) recommends 7-9 hours for the 18-25 years of young adults, a country representative sleep study in Bangladesh reported that $8.9 \%$ of young adults and adults sleep less than their recommended sleeping duration $[11,12]$. This poses them to suffer from the consequences of short term sleep duration that includes stress, somatic pain, poor quality of life, mood disorders, memory, and performance deficits $[13,14]$. 
Additionally, socio-demographic factors and socioeconomic inequalities are known to influence habitual sleep quality and quantity [15]. Previous study reported about $90 \%$ of university students need to share their rooms and faced sleep disturbances [16]. Another study reported about $60 \%$ of students suffer from poor sleep quality [17]. Many graduate students balance their academic responsibilities with their additional priorities of work, and family, and might be stressed which could eventually affect their sleep quality [18].

A study among Bangladeshi medical students demonstrated a significant positive association between internet addiction and sleep quality [19]. Previous studies also reported an association of internet addiction, problematic internet use, self-rated health and quality of life with sleep patterns among the Bangladeshi students [20-22]. Recent research indicates that college students get fatigued by a lack of sleep which eventually affects their academic performance and overall grades in exam [23]. It is, therefore, warranted to investigate the factors that interrupts the sleep quality among young adults. Earlier studies reported that inadequate sleep and sleep disturbance among university students can be due to a variety of factors including depression, anxiety, substance use, and academic or vocational needs [24,25]. Identifying the factors affecting sleep quality of university students could have major public health implications- firstly, they (15-24 yrs) contribute almost $20 \%$ of country's population and this group is to hold the hand of country's economy in near future; therefore, ensuring their quality of life is warranted. Previous efforts have been made to identify the factors associated with sleep quality among the student and young adult cohorts in different low middle-income countries $[8,26,27]$. However, no previous study reported the prevalence and factors associated with poor sleep quality among Bangladeshi university students. The study, therefore, investigated the prevalence and factors associated with sleep quality among the Bangladeshi university students.

\section{Method}

\section{Study design, participants, and procedure}

A cross-sectional survey was carried out among students of Patuakhali Science and Technology University (Bangladesh). Data were collected from August to October 2019. A total of 332 students participated in the study (response rate 94.5\%). The 'probability proportional to size' (PPS) technique was used to determine the number of students for each faculty. Data were collected face-to-face using a pre-tested structured questionnaire. The sampling frame was created by gathering student's registration numbers, collected from the 
respective faculty's Dean Office. Students were selected randomly using a lottery method from the sampling frame. Research assistants contacted the selected participants and carried out the face-to-face interviews following study protocol.

\section{Independent variables}

Socio-demographic and sleep variables: Data were collected, including the participant age, gender, monthly expenditure (amount in BDT), source of monthly income (family income or self-income), cigarette smoking (yes/no), and physical exercise (weekly). Additionally, several sleep-related questions were also asked the participants to capture their sleep-related information. Sleep variables includes; students' knowledge of age-specific recommended total sleep time based on National Sleep Foundation guidelines (i.e., 7-9 hours for an individual aged 18-25 years [12]) (yes/no), history of taking sleeping pills in last 10 days (yes/no), and Clock time of going to bed at night and wake-up (at $1 \mathrm{hr}$. interval). Since the study carried out among the student population, it was assumed that the subject area may influence sleep quality. Therefore, the study collected data on the student's subject areas in broad areas (i.e., biological science, engineering, or business study).

Bed-time social media use: Two items were asked to assess the bed-time social media use: (i) 'Do you use any kind of social media (regardless the platform such as Facebook, YouTube, Whatsapp, LinkedIn, or Twitter) just before you sleep?' and (ii) 'How long did you use social media while intended to bed for sleep (in minutes)?' Those who respond 'yes' in the first question were asked whether they spent more or less than one hour on social media before going to sleep. This generated a variable named 'Bed-time social media use' and responses were divided into three categories either 'No social media use', '<1-hour social media use', or ' $\geq 1$-hour social media use').

\section{Dependent variables}

Sleep quality: The Pittsburgh Sleep Quality Index (PSQI) was used to assess the (past month) sleep quality of the students [28]. The original English version was used because the participants were studying at the university level and all spoke English. The PSQI is one of the most frequently used tools to assess subjective sleep quality and has been validated among clinical and non-clinical populations [29] and used in previous Bangladeshi studies [19]. The scale differentiates sleep quality into two categories 'poor' and 'good' by assessing seven components: subjective sleep quality, sleep latency, sleep duration, habitual sleep efficiency, sleep disturbances, use of sleeping medications, and daytime dysfunction. The responses for 
each item are scored 0-3, and the total score was calculated by adding all the individual scores (total score 21). A total score of 5 or greater is indicative of poor sleep quality. For this present study, the Cronbach's alpha of the PSQI was found 0.73. A Cronbach's alpha value of 0.70 is reported sufficient to measure reliability [30,31].

\section{Statistical analysis}

Both descriptive and inferential statistics were used. Descriptive statistics were performed to calculate the frequency and percentage of the independent variables (i.e., sociodemographic variables). Chi-squared tests were performed to determine the association between sleep quality (good/poor) and explanatory categorical variables. Binary and multiple logistic regression analysis (both crude and adjusted) were conducted to determine the likelihood with $95 \%$ confidence intervals. The tests for the main effects were considered significant at 5\% level of significance. All statistical analyses were performed using the statistical software package STATA (version 14.2).

\section{Results}

The prevalence of poor sleep quality (PSQI $\geq 5)$ among the students was $66.6 \%(n=221)$, and the mean PSQI score was 5.97 ( $\mathrm{SD}=2.79)$ (Min-max: 1-14). Of the seven components of PSQI, the average score for subjective sleep latency among the participants was higher (1.42/ 3.00) compared to the other six components. Table 1 shows the participant's sociodemographic characteristics based on their sleep quality (good vs. poor). The average age of the participants was 21.6 years $(\mathrm{SD}=1.7)$, with an age range of $18-25$ years. The majority of the participants were male $(64.5 \%)$ and more than half of the students $(62.3 \%)$ reported that they knew about age-specific recommended sleep time. Around two-thirds of participants had an actual sleep duration of less than seven hours per night (61.7\%) with an average of 6.33 hours $(\mathrm{SD}=1.1)$. The prevalence of poor sleep quality was significantly higher among (i) females $(81.4 \% ; p<.001)$, (ii) those who consumed sleeping pills in past 10 days $(88.5 \%$; $p=.014$ ), (iii) those who did not have knowledge of recommended sleep hours $(73.6 \% ; p=.035)$, (iv) those who usually got up in the morning before 6 am $(80 \% ; p=.029)$, (v) those who slept less than seven hours at night $(81.5 \% ; p<.001)$, and (vi) those who used social media less than one hour before going to bed at night $(74 \% ; p=.001)$. Poor sleep quality was not significantly associated with study subject areas meaning that pressure from specific subjects (either biological science, engineering, or business study) areas did not appear to contribute to the poor sleep quality. 
Both crude and adjusted odds ratios (ORs) are presented in Table 2. CORs suggest that females had a 3.1 times higher risk of having poor sleep quality $(\mathrm{COR}=3.10,95 \% \mathrm{CI}$ : 1.81 $5.31, p<.001)$ compared to males. However, the odds became even higher after adjusting for socio-demographic variables such as student's gender, consumption of sleeping pills in last 10 days, knowledge on recommended sleep time for their age group, time of getting up in the morning, numbers of hours sleep a night, and social media use before sleep time at night. $(\mathrm{AOR}=4.12,95 \% \mathrm{CI}: 2.15-7.86, p<.001)$. Students from biological sciences had about $45 \%$ higher chance of being poor sleepers than business study students (COR=1.45, 95\% CI: 0.83 $2.55, p=.187)$. In contrast, higher odds were found for the engineering students in the adjusted model $(\mathrm{AOR}=1.69,95 \% \mathrm{CI}: 0.56-5.09, p=.346)$. However, both associations were nonsignificant.

Students who had a history of taking sleeping pills in the past 10 days had a 4.1 times higher risk of being poor sleeper $(\mathrm{COR}=4.18,95 \% \mathrm{CI}$ : 1.22-14.24, $\mathrm{p}=.022)$. Those who did not know the recommended sleep hours had a $68 \%$ chance of poor sleep quality $(\mathrm{COR}=1.68$, $95 \%$ CI: $1.03-2.74, p=.036)$ compared to those that did. Students who usually slept less than seven hours at night had approximately six times higher risk of being poor sleeper $(\mathrm{COR}=5.94$, 95\% CI: 3.61-9.77, $p<.001)$ compared with those who slept seven hours or more. The possibility of being poor sleeper became higher in the adjusted model (AOR $=8.41,95 \% \mathrm{CI}$ : 4.42-16.01, $p<.001$ ) among those who slept less than seven hours at night. The study found that the duration of bedtime social media use was highly associated with poor sleep quality. Those who used social media less than one hour before bedtime were 2.2 times more likely to have poor sleep quality compared to those who did not use social media before bedtime at all after adjusting with potential socio-demographic variables. Furthermore, the adjusted model doubled the likelihood of poor sleep quality among those who used social media for more than one hour before bed-time ( $\mathrm{AOR}=4.33,95 \% \mathrm{CI}: 1.38-13.51, p=.012)$.

\section{Discussion}

The present study assessed the association of various factors (bedtime social media use, cigarette smoking, physical activity, subject studied) alongside socio-demographic characteristics with sleep quality among the university students in Bangladesh. The findings showed that being female, having less sleep a night, and spending more than an hour using social media before sleep were independent predictors of poor sleep quality among Bangladeshi university students. The study found that the frequency of poor sleep quality (using the PQSI) was $66.6 \%$ which was very similar to the study examining Bangladeshi 
medical students which reported $69.5 \%$ poor sleep quality [19]. Afandi and his colleagues also reported similar poor sleep quality (67.2\%) among Arabic university students [32].

The present study found significant gender differences in sleep quality among females who were significantly more likely to report poorer sleep quality. It is not entirely clear why females reported a higher proportion of poor sleep quality since both males and females resided in the same university setting and had the same study pressure. However, another previous study reported that females being more likely to report sleep complaints without explaining the underlying reason [33]. The present study found a similar trend among female students (3.1 times higher poorer sleep quality than male students). However, other studies have reported the opposite with male students being more likely than female students to have poor sleep quality $[19,34]$. Female susceptibility for the poor sleep quality may be influenced by gender variation in the biology of sleep [30] or some other variables (e.g., stress, family history of poor sleep) that were not specifically assessed in the present study $[29,35]$.

The present study also found that sleep quality was significantly associated with participants' consumption of sleeping pills in the past 10 days, getting up before $6 \mathrm{am}$, and the number of hours of sleep time at night. These associations may be due to the study pressure and the uncertainty of their future career which may contribute to increased psychological pressure (e.g., stress and anxiety) [36,37]. However, this is purely speculative. It is reasonable to assume that increased psychological pressure may result in students using sleeping pills. Getting up very early in the morning may be indicative of fewer numbers of hours slept at night which would also impact sleep quality. It was also found that those who knew age-specific recommended sleeping time had better sleep quality than those who did not $[38,39]$. This finding suggests that increasing knowledge concerning age-specific sleep could be one of the potential solutions to minimizing poor sleep quality among Bangladeshi university students.

Besides, the present study found a significant association between the duration of social media use before bed-time and sleep quality (i.e., the more social media used before bed-time, the worse the sleep quality). Previous studies have reported that poor sleep quality is highly prevalent among students who use social networking websites and watch television before going to bed [40]. The present study's findings indicate that students who used social media for an hour or more before bedtime were 4.4 times more likely to experience poor sleep quality than those who did not use social media before bedtime. The study's findings are consistent with those of Garett et al. (2016) and Levenson et al. (2016) who found the same thing [25,41]. In the past few years, there has been a notable increase in the use of smartphones to access 
different social networking sites in Bangladesh [42]. Poor sleep quality may also be explained due to the artificial blue light that emits from the electronic devices, mainly from smartphones. Such blue light suppresses the release of the body's melatonin, a sleep-inducing hormone [43].

Problematic social media use has increased, especially in the developing world with the most substantial proportion of users being young individuals [44]. In Bangladesh, the 'Digital Bangladesh' movement was launched by the government to promote information technology. Consequently, the number of internet subscribers has increased over the last few years since launching the movement [22]. Therefore, it is reasonable to assume that social media use and poor sleep quality are likely to increase in Bangladesh in the coming years if proper sleep education is not ensured. Several studies have reported a consistently higher prevalence of problematic social media use among university students compared to other cohorts $[45,46]$. However, only a few studies have examined sleep quality issues [19-22,47,48].

Authors also assumed that variation in type of subject studied may have influenced sleep quality. However, no such relationship was found. Furthermore, it was thought that economic status may have influenced sleep quality, but no such relationship was found. Additionally, it was assumed that the source of monthly income might be another predictor because of the thoughts that, those who need to find their own money for their monthly expenditures (through part-time job or tuition) rather than rely on their parents, may lead to financial insecurity which may eventually affect sleep quality. However, no such relationship was found.

The present study is not immune to limitations. First, it is limited by self-reported sleep data and not verified by other means (i.e., objective quantification) which could not be carried out due to privacy issues and lack of access to sleep trackers. Second, the study was crosssectional in nature and therefore was unable to provide an indication of causality between any of the variables examined. Therefore, the authors advise caution while interpreting the results. Additionally, the sample size was not country representative of all university students. However, we used Probability Proportional to Size (PPS) technique during sampling to minimize the study's limitations and estimation biases. Future studies should overcome such limitations by employing longitudinal designs with larger and more representative samples.

\section{Conclusion}


Prevalence of poor sleep quality was found high among Bangladeshi university students. Being female, having less sleep a night, and spending more than one-hour using social media before bedtime were the independent predictors for poor sleep quality.

\section{Declarations}

Funding: The authors did not receive any external source of funding for this study.

Conflict of interest: The authors declare that they have no conflict of interests.

Ethical approval: Study protocol was approved by the Institutional Ethical Committee (IEC) of Patuakhali Science and Technology University, Patuakhali, Bangladesh (reference no. PSTU/IEC/2019/03; Date: 10-07-2019).

Informed consent: Written informed consent and assent were obtained from both the participants and their respective parents.

Consent for publication: All authors have read and approved the submission.

Availability of data and material: After considering all aspects of ethical issue and as per existing rule, anonymized data may be shared with qualified researchers.

Code availability: Not applicable.

Authors' contributions: MSA: Conceptualization, Data curation, Formal analysis, Writing original draft, Validation. SK: writing - original draft, Validation, KH: writing - original draft, Validation, LCS: Writing - review \& editing, Validation, FMY: Conceptualization, Data analysis, Writing - review \& editing, Validation, MDG: Writing - review \& editing, Validation.

\section{References}

1. FERRI R, MANCONI M, PLAZZI G, BRUNI O, VANDI S, MONTAGNA P, et al. A quantitative statistical analysis of the submentalis muscle EMG amplitude during sleep in normal controls and patients with REM sleep behavior disorder. J Sleep Res. 2008;17:89100.

2. Jin W, Wang A, Ma J, Lin Q. Effects of electromagnetic induction and noise on the regulation of sleep wake cycle. Sci China Technol Sci. 2019;62:2113-9.

3. Short MA, Louca M. Sleep deprivation leads to mood deficits in healthy adolescents. Sleep 
Med. 2015;16:987-93.

4. Bin YS. Is Sleep Quality More Important than Sleep Duration for Public Health? Sleep. 2016;39:1629-30.

5. Lee SY, Ju YJ, Lee JE, Kim YT, Hong SC, Choi YJ, et al. Factors associated with poor sleep quality in the Korean general population: Providing information from the Korean version of the Pittsburgh Sleep Quality Index. J Affect Disord. 2020;271:49-58.

6. Kline C. Sleep Quality. Encycl Behav Med. New York, NY: Springer New York; 2013. p. $1811-3$

7. Porth C. Essentials of pathophysiology: concepts of altered health states. 8th editio. New York, NY, USA: Wolters Kluwer Health Lippincott Williams \& Wilkins; 2009.

8. Berhanu H, Mossie A, Tadesse S, Geleta D. Prevalence and Associated Factors of Sleep Quality among Adults in Jimma Town, Southwest Ethiopia: A Community-Based CrossSectional Study. Sleep Disord. 2018;2018:1-10.

9. Hale L. Who has time to sleep? J Public Health (Bangkok). 2005;27:205-11.

10. Stranges S, Dorn JM, Shipley MJ, Kandala N-B, Trevisan M, Miller MA, et al. Correlates of Short and Long Sleep Duration: A Cross-Cultural Comparison Between the United Kingdom and the United States: The Whitehall II Study and the Western New York Health Study. Am J Epidemiol. 2008;168:1353-64.

11. Yunus FM, Khan S, Akter T, Jhohura FT, Reja S, Islam A, et al. How many hours do people sleep in Bangladesh? A country-representative survey. J Sleep Res. 2016;25:365-76.

12. National Sleep Foundation. National Sleep Foundation Recommends New Sleep Times [Internet]. 2020 [cited $2020 \mathrm{Jul}$ 27]. Available from: https://www.sleepfoundation.org/pressrelease/national-sleep-foundation-recommendsnew-\%0Asleep-times

13. Medic G, Wille M, Hemels M. Short- and long-term health consequences of sleep disruption. Nat Sci Sleep. 2017;9:151-61.

14. Yunus FM, Khan S, Mitra DK, Mistry SK, Afsana K, Rahman M. Relationship of sleep pattern and snoring with chronic disease: findings from a nationwide population-based survey. Sleep Heal. 2018;4:40-8.

15. Grandner MA, Patel NP, Gehrman PR, Xie D, Sha D, Weaver T, et al. Who gets the best sleep? Ethnic and socioeconomic factors related to sleep complaints. Sleep Med. 
$2010 ; 11: 470-8$.

16. Buboltz WC, Brown F, Soper B. Sleep Habits and Patterns of College Students: A Preliminary Study. J Am Coll Heal. 2001;50:131-5.

17. Lund HG, Reider BD, Whiting AB, Prichard JR. Sleep Patterns and Predictors of Disturbed Sleep in a Large Population of College Students. J Adolesc Heal. 2010;46:124-32. 18. Oswalt SB, Wyatt TJ. Who Needs More Sleep? Comparing Undergraduate and Graduate Students' Sleep Habits in a National U.S. Sample. Int J High Educ. 2014;4:77-85.

19. Jahan SM, Hossain SR, Sayeed UB, Wahab A, Rahman T, Hossain A. Association between internet addiction and sleep quality among students: a cross-sectional study in Bangladesh. Sleep Biol Rhythms. 2019;17:323-9.

20. Ahmed M, Sen L, Griffiths M. Association between self-rated health and quality of life with sleep quality among bangladeshi university students. Soc Heal Behav. 2020;3:35-7. 21. Islam MA, Hossin MZ. Prevalence and risk factors of problematic internet use and the associated psychological distress among graduate students of Bangladesh. Asian J Gambl Issues Public Heal. 2016;6:11.

22. Mamun MA, Rafi MA, Al Mamun AHMS, Hasan MZ, Akter K, Hsan K, et al. Prevalence and Psychiatric Risk Factors of Excessive Internet Use among Northern Bangladeshi Job-Seeking Graduate Students: A Pilot Study. Int J Ment Health Addict. $2019 ; 1-11$

23. Reynolds AM, Shell MD. 0726 The Impact of Sleep on GPA and Internalizing Symptoms in College Students. Sleep. 2018;41:A269-70.

24. Hershner S, Chervin R. Causes and consequences of sleepiness among college students. Nat Sci Sleep. 2014;6:73-84.

25. Levenson JC, Shensa A, Sidani JE, Colditz JB, Primack BA. The association between social media use and sleep disturbance among young adults. Prev Med (Baltim). 2016;85:3641.

26. Mwape RK, Mulenga D. Consumption of Energy Drinks and Their Effects on Sleep Quality among Students at the Copperbelt University School of Medicine in Zambia. Sleep Disord. 2019;2019:1-7.

27. Ghrouz AK, Noohu MM, Dilshad Manzar M, Warren Spence D, BaHammam AS, Pandi- 
Perumal SR. Physical activity and sleep quality in relation to mental health among college students. Sleep Breath. 2019;23:627-34.

28. Buysse DJ, Reynolds CF, Monk TH, Berman SR, Kupfer DJ. The Pittsburgh sleep quality index: A new instrument for psychiatric practice and research. Psychiatry Res. 1989;28:193213.

29. Almojali AI, Almalki SA, Alothman AS, Masuadi EM, Alaqeel MK. The prevalence and association of stress with sleep quality among medical students. J Epidemiol Glob Health. 2017;7:169.

30. Taber KS. The Use of Cronbach's Alpha When Developing and Reporting Research Instruments in Science Education. Res Sci Educ. 2018;48:1273-96.

31. Bland JM, Altman DG. Statistics notes: Cronbach's alpha. BMJ. 1997;314:572-572.

32. Afandi O, Hawi H, Mohammed L, Salim F, Hameed AK, Shaikh RB, et al. Sleep quality among university students: Evaluating the impact of smoking, social media use, and energy drink consumption on sleep quality and anxiety. Inq J. 2013;5.

33. KRONHOLM E, HARMA M, HUBLIN C, ARO AR, PARTONEN T. Self-reported sleep duration in Finnish general population. J Sleep Res. 2006;15:276-90.

34. Ak Ş, Koruklu N, Y1lmaz Y. A Study on Turkish Adolescent's Internet Use: Possible Predictors of Internet Addiction. Cyberpsychology, Behav Soc Netw. 2013;16:205-9.

35. Sehgal A, Mignot E. Genetics of Sleep and Sleep Disorders. Cell. 2011;146:194-207.

36. Al-Khani AM, Sarhandi MI, Zaghloul MS, Ewid M, Saquib N. A cross-sectional survey on sleep quality, mental health, and academic performance among medical students in Saudi Arabia. BMC Res Notes. 2019;12:665.

37. Alsaggaf M, Wali S, Merdad R, Merdad L. Sleep quantity, quality, and insomnia symptoms of medical students during clinical years. Relationship with stress and academic performance. Saudi Med J. 2016;37:173-82.

38. Al-Kandari S, Alsalem A, Al-Mutairi S, Al-Lumai D, Dawoud A, Moussa M. Association between sleep hygiene awareness and practice with sleep quality among Kuwait University students. Sleep Heal. 2017;3:342-7.

39. Dietrich SK, Francis-Jimenez CM, Knibbs MD, Umali IL, Truglio-Londrigan M. Effectiveness of sleep education programs to improve sleep hygiene and/or sleep quality in 
college students. JBI Database Syst Rev Implement Reports. 2016;14:108-34.

40. Tavernier R, Willoughby T. Sleep problems: predictor or outcome of media use among emerging adults at university? J Sleep Res. 2014;23:389-96.

41. Garett R, Liu S, Young SD. The relationship between social media use and sleep quality among undergraduate students. Information, Commun Soc. 2018;21:163-73.

42. Dhaka Tribune. 4.1\% growth in local mobile phone market in 2019 | Dhaka Tribune [Internet]. [cited 2020 Jul 27]. Available from:

https://www.dhakatribune.com/business/2020/02/24/4-1-growth-in-local-mobile-phonemarket-in-2019

43. Harvard Medical School. Blue light has a dark side - Harvard Health [Internet]. [cited $2020 \mathrm{Jul}$ 27]. Available from: https://www.health.harvard.edu/staying-healthy/blue-light-hasa-dark-side

44. Oche OM, Gana GJ, Yahaya M, Khalid I, Sambo MLA. Prevalence and Effect of Social Media on Sleep among Students of Higher Institutions in Sokoto Metropolis, Sokoto State Nigeria. Ann Med Health Sci Res. Annals of Medical and Health Sciences Research; 2019;9:729-35.

45. Poorolajal J, Ahmadpoor J, Mohammadi Y, Soltanian AR, Asghari SZ, Mazloumi E. Prevalence of problematic internet use disorder and associated risk factors and complications among Iranian university students: a national survey. Heal Promot Perspect. 2019;9:207-13. 46. Andreassen CS, Pallesen S, Griffiths MD. The relationship between addictive use of social media, narcissism, and self-esteem: Findings from a large national survey. Addict Behav. 2017;64:287-93.

47. Uddin MS, Mamun A Al, Iqbal MA, Nasrullah M, Asaduzzaman M, Sarwar MS, et al. Internet Addiction Disorder and Its Pathogenicity to Psychological Distress and Depression among University Students: A Cross-Sectional Pilot Study in Bangladesh. Psychology. 2016;07:1126-37.

48. Karim AKMR, Nigar N. The Internet Addiction Test: Assessing its psychometric properties in Bangladeshi culture. Asian J Psychiatr. 2014;10:75-83. 
Table 1. Chi-square test analysis of the study variables and sleep quality among university students and distribution of PSQI scores $(n=332)$.

\begin{tabular}{|c|c|c|c|c|c|c|}
\hline \multirow[t]{2}{*}{ Characteristics } & \multirow{2}{*}{$\begin{array}{c}\text { Frequency } \\
(\%)\end{array}$} & \multicolumn{2}{|c|}{ Sleep quality (\%) } & \multirow[t]{2}{*}{$\chi^{2}(\mathrm{df})$} & \multirow[t]{2}{*}{$p$-value } & \multirow{2}{*}{$\begin{array}{l}\text { PSQI Score } \\
\text { (Mean } \pm \\
\text { SD) }\end{array}$} \\
\hline & & Good & Poor & & & \\
\hline \multicolumn{7}{|l|}{ Age (years) } \\
\hline $18-21$ & $168(50.6)$ & 32.1 & 67.9 & $0.25(1)$ & \multirow[t]{2}{*}{0.614} & $6.29 \pm 2.92$ \\
\hline $22-25$ & $164(49.4)$ & 34.8 & 65.2 & & & $5.65 \pm 2.62$ \\
\hline \multicolumn{7}{|l|}{ Gender } \\
\hline Male & $214(64.5)$ & 41.6 & 58.4 & $17.99(1)$ & \multirow[t]{2}{*}{$<0.001 *$} & $5.29 \pm 2.61$ \\
\hline Female & $118(35.5)$ & 18.6 & 81.4 & & & $7.21 \pm 2.68$ \\
\hline \multicolumn{7}{|l|}{ Study program } \\
\hline Bachelor & $258(77.7)$ & 32.6 & 67.4 & $0.39(1)$ & \multirow[t]{2}{*}{0.528} & $6.16 \pm 2.90$ \\
\hline Masters & $74(22.3)$ & 36.5 & 63.5 & & & $5.34 \pm 2.27$ \\
\hline \multicolumn{7}{|l|}{ Study field } \\
\hline Biological science & $237(71.4)$ & 31.6 & 68.4 & $1.78(2)$ & \multirow[t]{3}{*}{0.411} & $6.03 \pm 2.74$ \\
\hline Engineering & $28(8.4)$ & 32.1 & 67.9 & & & $6.64 \pm 3.45$ \\
\hline Business study & $67(20.2)$ & 40.3 & 59.7 & & & $5.51 \pm 2.61$ \\
\hline \multicolumn{7}{|c|}{ Monthly living expenditure (BDT) } \\
\hline$\leq 5,000$ & $139(41.9)$ & 31.7 & 68.3 & $0.55(2)$ & \multirow[t]{3}{*}{0.757} & $6.19 \pm 2.95$ \\
\hline $5,001-10,000$ & $186(56.0)$ & 34.4 & 65.6 & & & $5.81 \pm 2.67$ \\
\hline $10,000+$ & $7(2.1)$ & 42.9 & 57.1 & & & $6.00 \pm 2.44$ \\
\hline \multicolumn{7}{|c|}{ Source of monthly income } \\
\hline Family income & $274(82.5)$ & 32.8 & 67.2 & $0.24(1)$ & \multirow[t]{2}{*}{0.622} & $5.99 \pm 2.69$ \\
\hline Self-income & $58(17.5)$ & 36.2 & 63.8 & & & $5.91 \pm 3.25$ \\
\hline \multicolumn{7}{|l|}{ Physical exercise } \\
\hline No & $205(61.7)$ & 32.7 & 67.3 & $0.44(2)$ & \multirow[t]{3}{*}{0.800} & $6.04 \pm 2.72$ \\
\hline$<3$ times/week & $62(18.7)$ & 32.3 & 67.7 & & & $6.10 \pm 3.11$ \\
\hline$\geq 3$ times/week & $65(19.6)$ & 36.9 & 63.1 & & & $5.63 \pm 2.70$ \\
\hline \multicolumn{7}{|l|}{ Smoking status } \\
\hline Smoker & $90(27.1)$ & 31.1 & 68.9 & $0.29(1)$ & 0.584 & $6.32 \pm 2.76$ \\
\hline Non-smoker & $242(72.9)$ & 34.3 & 65.7 & & & $5.84 \pm 2.79$ \\
\hline Sleeping pill consun & last 10 days) & & & & & \\
\hline Yes & $26(7.8)$ & 11.5 & 88.5 & $6.07(1)$ & $0.014 *$ & $8.38 \pm 3.51$ \\
\hline No & $306(92.2)$ & 35.3 & 64.7 & & & $5.77 \pm 2.62$ \\
\hline Knowledge of re & d sleep time & & & & & \\
\hline Yes & $207(62.3)$ & 37.7 & 62.3 & $4.45(1)$ & $0.035^{*}$ & $5.86 \pm 2.92$ \\
\hline No & $125(37.7)$ & 26.4 & 73.6 & & & $6.16 \pm 2.56$ \\
\hline Time of going to & & & & & & \\
\hline Before 00:00 & $39(11.7)$ & 35.9 & 64.1 & $7.42(4)$ & 0.115 & $5.67 \pm 2.99$ \\
\hline 00:00-00:59 & $159(47.9)$ & 37.1 & 62.9 & & & $5.75 \pm 2.73$ \\
\hline 01:00-01:59 & $59(17.8)$ & 37.3 & 62.7 & & & $5.69 \pm 2.53$ \\
\hline 02:00-02:59 & $52(15.7)$ & 25.0 & 75.0 & & & $6.23 \pm 2.77$ \\
\hline After 03:00 & $23(6.9)$ & 13.0 & 87.0 & & & $8.13 \pm 2.78$ \\
\hline Time of getting & orning & & & & & \\
\hline Before 06:00 & $20(6.0)$ & 20.0 & 80.0 & $10.75(4)$ & $0.029 *$ & $6.70 \pm 2.63$ \\
\hline 06:00-06:59 & $44(13.3)$ & 43.2 & 56.8 & & & $5.14 \pm 2.68$ \\
\hline 07:00-07:59 & $103(31.0)$ & 23.3 & 76.7 & & & $6.40 \pm 2.67$ \\
\hline 08:00-08:59 & $88(26.5)$ & 40.9 & 59.1 & & & $5.69 \pm 2.89$ \\
\hline After 09:00 & $77(23.2)$ & 36.4 & 63.6 & & & $6.01 \pm 2.84$ \\
\hline Actual sleep tir & & & & & & \\
\hline$<7$ hour & $205(61.7)$ & 18.5 & 81.5 & $53.43(1)$ & & $6.86 \pm 2.70$ \\
\hline
\end{tabular}




\begin{tabular}{|c|c|c|c|c|c|c|}
\hline$\geq 7$ hour & $127(38.3)$ & 57.5 & 42.5 & & $<0.001 *$ & $4.54 \pm 2.30$ \\
\hline \multicolumn{7}{|c|}{ Bed-time social media use } \\
\hline No & $18(5.4)$ & 61.1 & 38.9 & $14.50(2)$ & \multirow[t]{3}{*}{$0.001 *$} & $4.50 \pm 2.87$ \\
\hline$<1$ hour & $118(35.5)$ & 41.5 & 58.5 & & & $5.26 \pm 2.53$ \\
\hline$\geq 1$ hour & $196(59.0)$ & 26.0 & 74.0 & & & $6.54 \pm 2.80$ \\
\hline Overall & 322 & 33.4 & 66.6 & & & $5.97 \pm 2.79$ \\
\hline
\end{tabular}


Table 2. Relationship of bed-time social media use and socio-demographics with sleep quality $(n=332)$

\begin{tabular}{|c|c|c|c|c|c|c|}
\hline \multirow[t]{2}{*}{ Characteristics } & \multicolumn{3}{|c|}{ Crude } & \multicolumn{3}{|c|}{ Adjusted $^{\text {a }}$} \\
\hline & OR & $95 \% \mathrm{CI}$ & $p$-value & OR & $95 \% \mathrm{CI}$ & $p$-value \\
\hline \multicolumn{7}{|l|}{ Age (years) } \\
\hline $18-21$ & 1.12 & $0.71-1.77$ & 0.614 & 0.72 & $0.41-1.27$ & 0.265 \\
\hline $22-25$ & 1.00 & & & 1.00 & & \\
\hline \multicolumn{7}{|l|}{ Gender } \\
\hline Male & 1.00 & & & 1.00 & & \\
\hline Female & 3.10 & $1.81-5.31$ & $<0.001 *$ & 4.12 & $2.15-7.86$ & $<0.001 *$ \\
\hline \multicolumn{7}{|l|}{ Study program } \\
\hline Bachelor & 1.19 & $0.69-2.04$ & 0.528 & 0.72 & $0.369-1.40$ & 0.334 \\
\hline Masters & 1.00 & & & 1.00 & & \\
\hline \multicolumn{7}{|l|}{ Study discipline } \\
\hline Biological science & 1.45 & $0.83-2.55$ & 0.187 & 1.11 & $0.55-2.21$ & 0.765 \\
\hline Engineering & 1.42 & $0.56-3.61$ & 0.456 & 1.69 & $0.56-5.09$ & 0.346 \\
\hline Business study & 1.00 & & & 1.00 & & \\
\hline \multicolumn{7}{|c|}{ Monthly living expenditure (BDT) } \\
\hline$\leq 5,000$ & 1.61 & $0.34-7.54$ & 0.539 & 1.39 & $0.245-7.89$ & 0.710 \\
\hline $5,001-10,000$ & 1.43 & $0.31-6.58$ & 0.646 & 1.36 & $0.245-7.65$ & 0.721 \\
\hline $10,000+$ & 1.00 & & & 1.00 & & \\
\hline \multicolumn{7}{|c|}{ Source of monthly income } \\
\hline Family income & 1.16 & $0.64-2.09$ & 0.622 & 1.01 & $0.47-2.15$ & 0.971 \\
\hline Self-income & 1.00 & & & 1.00 & & \\
\hline \multicolumn{7}{|l|}{ Physical exercise } \\
\hline No & 1.20 & $0.67-2.15$ & 0.529 & 0.97 & $0.47-1.99$ & 0.947 \\
\hline$<3$ times/week & 1.22 & $0.59-2.55$ & 0.581 & 1.11 & $0.46-2.68$ & 0.815 \\
\hline$\geq 3$ times/week & 1.00 & & & 1.00 & & \\
\hline \multicolumn{7}{|l|}{ Smoking status } \\
\hline Smoker & 1.15 & $0.68-1.94$ & 0.584 & 1.17 & $0.58-2.35$ & 0.647 \\
\hline Non-smoker & 1.00 & & & 1.00 & & \\
\hline \multicolumn{7}{|c|}{ Sleeping pill consumption (last 10 days) } \\
\hline Yes & 4.18 & $1.22-14.24$ & $0.022 *$ & 3.66 & $0.93-14.32$ & 0.062 \\
\hline No & 1.00 & & & 1.00 & & \\
\hline \multicolumn{7}{|c|}{ Knowledge of recommended sleep time } \\
\hline Yes & 1.00 & & & 1.00 & & \\
\hline No & 1.68 & $1.03-2.74$ & $0.036^{*}$ & 1.16 & $0.92-2.89$ & 0.094 \\
\hline \multicolumn{7}{|c|}{ Time of going to bed at night } \\
\hline Before 00:00 & 1.00 & & & 1.00 & & \\
\hline 00:00-00:59 & 0.94 & $0.45-1.96$ & 0.888 & 0.51 & $0.18-1.42$ & 0.202 \\
\hline 01:00-01:59 & 0.94 & $0.40-2.18$ & 0.889 & 0.71 & $0.20-2.43$ & 0.586 \\
\hline 02:00-02:59 & 1.68 & $0.67-4.16$ & 0.262 & 0.91 & $0.21-3.80$ & 0.900 \\
\hline After 03:00 & 3.73 & $0.94-14.81$ & 0.061 & 1.85 & $0.27-12.43$ & 0.523 \\
\hline \multicolumn{7}{|c|}{ Time of getting up in the morning } \\
\hline Before 06:00 & 2.28 & $0.69-7.51$ & 0.173 & 0.44 & $0.10-1.8$ & 0.261 \\
\hline 06:00-06:59 & 0.75 & $0.35-1.60$ & 0.460 & 0.29 & $0.11-0.76$ & $0.012^{*}$ \\
\hline 07:00-07:59 & 1.88 & $0.98-3.60$ & 0.057 & 0.66 & $0.29-1.52$ & 0.335 \\
\hline 08:00-08:59 & 0.82 & $0.44-1.54$ & 0.550 & 0.67 & $0.31-1.42$ & 0.300 \\
\hline After 09:00 & 1.00 & & & 1.00 & & \\
\hline \multicolumn{7}{|c|}{ Actual sleep time at night } \\
\hline$<7 \mathrm{hr}$. & 5.94 & $3.61-9.77$ & $<0.001^{*}$ & 8.41 & $4.42-16.01$ & $<0.001^{*}$ \\
\hline$\geq 7 \mathrm{hr}$. & 1.00 & & & 1.00 & & \\
\hline
\end{tabular}


Social media use before sleep time at night

\begin{tabular}{|l|l|c|c|c|c|c|c|}
\hline & No & 1.00 & & & 1.00 & & \\
\hline & $<1$ hour & 2.21 & $0.80-6.11$ & 0.125 & 1.75 & $0.55-5.51$ & 0.334 \\
\hline & $\geq 1$ hour & 4.46 & $1.64-12.14$ & $0.003^{*}$ & 4.33 & $1.38-13.51$ & $0.012^{*}$ \\
\hline
\end{tabular}

a Adjusted with student's gender, consumption of sleeping pills in last 10 days, knowledge on recommended sleep time for their age group, time of getting up in the morning, actual sleep time at night and social media use before sleep time at night.

*Significant $\mathrm{p}$-value $(\mathrm{p}<0.05)$

BDT: Bangladeshi Taka (1000 BDT about 12 US\$) 